\title{
Minimal important difference of the transition dyspnoea index in a multinational clinical trial
}

\author{
T.J. Witek Jr*, D.A. Mahler\#
}

\begin{abstract}
Minimal important difference of the transition dyspnoea index in a multinational clinical trial. T.J. Witek Jr, D. A. Mahler. (C)ERS Journals Ltd 2003.

ABSTRACT: Dyspnoea is a primary symptom of chronic obstructive pulmonary disease (COPD). The baseline (BDI) and transition (TDI) dyspnoea indices are commonly used instruments to assess breathlessness and the impact of intervention. Its validity and pattern of response in multinational clinical trials has not been established.

In a retrospective analysis of a cohort of 997 COPD patients who received tiotropium, salmeterol or placebo, in addition to usual care, the validity and pattern of response of the BDI and TDI were examined.

The BDI was significantly correlated with the dyspnoea diary (DD) score and the symptom and activity components of the St. George's respiratory questionnaire (SGRQ), establishing concurrent validity. Furthermore, the TDI was also correlated with the changes in DD, SGRQ symptom and activity scores. Construct validity was established by the association between baseline forced expiratory volume in one second (FEV1) and BDI and $\triangle F E V 1$ with TDI. Physician's global evaluation (PGE) was significantly associated with BDI as well as $\triangle$ PGE with TDI. Significant correlations have also been observed when the cohorts were classified according to native English and native non-English speaking countries. A change in PGE of 1 category (i.e. 2 units on an 8-point scale) was associated with a mean TDI of $\sim 1$ unit (0.9-1.3 mean focal score), lending further support to the clinical significance of this change inherent in the instrument's descriptors. TDI responders (i.e. focal score $\geqslant 1$ unit) used less supplemental salbutamol, had fewer exacerbations and had significantly improved health status as measured by impacts and total SGRQ scores compared with nonresponders.

In conclusion, the transition dyspnoea index is a valid instrument when used in a multinational clinical trial and the patterns of response confirm a 1-unit change in the transition dyspnoea index focal score as being clinically important.
\end{abstract}

Eur Respir J 2003; 21: 267-272.

\author{
* Respiratory Development and Opera- \\ tions, Boehringer Ingelheim $\mathrm{GmbH}$, \\ Ingelheim, Germany. ${ }^{\#}$ Dartmouth- \\ Hitchcock Medical Center, Lebanon, \\ NH, USA.
}

Correspondence: T.J. Witek Jr, Boehringer Ingelheim $\mathrm{GmbH}$, Binger Strasse 173, 55216 Ingelheim am Rhein, Germany.

Fax: 496132776187

E-mail: witek@ing.boehringer-ingelheim. com

Keywords: Chronic obstructive pulmonary disease

dyspnoea

symptoms

tiotropium

transition dyspnoea index

Received: July 312002

Accepted after revision: August 272002

Supported by Boehringer Ingelheim Pharmaceuticals, Inc. Presented, in part, at the American Thoracic Society Meeting, May 2002.
Dyspnoea is the primary symptom of chronic obstructive lung disease (COPD) [1, 2] and its relief is a primary goal of therapy $[3,4]$. In the evaluation of pharmacotherapy for COPD, several instruments are available to provide a discriminative and evaluative assessment of dyspnoea [4]. Among these are the baseline (BDI) and transition (TDI) dyspnoea indices, which assess breathlessness in domains related to functional impairment, magnitude of task and magnitude of effort [5].

The reliability [5-7] and validity [5-8] of the BDI have been reported. The responsiveness to therapy has been shown by improvements in the TDI following both pharmacological [9-13] and nonpharmacological [14-20] interventions. Furthermore, the TDI was evaluated in an observational cohort over a 2-yr observation in patients with moderate COPD $(44 \%$ predicted forced expiratory volume in one second $(\mathrm{FEV} 1)$ ) and a reduction of nearly 1 unit in focal score was observed [21]. Finally, the validity of the BDI/ TDI based on its association with other related measures has also been demonstrated [22].
The utility of an instrument such as the BDI/TDI in the evaluation of pharmacological therapy requires that the validity established during its development is demonstrated within the investigation intended to establish the attribute of improved dyspnoea. The trial cohorts can also be used to establish the effect size that can be regarded as clinically meaningful by associating overall improvements in patient wellness with dyspnoea scores. For example, the current authors have recently reported the validity and meaningful differences in a cohort of patients from two identical registration trials in the USA [22]. In this report, these observations are confirmed and expanded in a cohort of patients participating in a multinational trial programme in 18 countries [23-24].

\section{Methods}

\section{Study design}

Eighty-nine clinical centres in 18 countries participated in two identical double-blind, double-dummy, 
parallel-group trials comparing tiotropium, salmeterol and placebo. The trial protocols were identical with the exception that one evaluated spirometry for $12 \mathrm{~h}$ postdosing and the other for $3 \mathrm{~h}$. Of the 18 countries, seven were native English speaking (Australia, Canada, Ireland, New Zealand, South Africa, UK and USA) and eleven were classified as non-native English speaking countries (Austria, Belgium, Denmark, Finland, France, Germany, Italy, the Netherlands, Norway, Spain and Sweden). The study groups consisted of outpatients of either sex who were $\geqslant 40 \mathrm{yrs}$ old and had a clinical diagnosis of COPD, as defined by the American Thoracic Society [25]. Participants were required to have at least a 10 pack-yr smoking history and clinically stable airway obstruction as defined as a FEV $1 \leqslant 60 \%$ pred normal values and FEV $1 \leqslant 70 \%$ of forced vital capacity (FVC). Patients with a history of asthma or daytime oxygen use were not allowed to participate.

A 2-week baseline period preceded randomisation to tiotropium (18 $\mu \mathrm{g}$ once daily), salmeterol $(50 \mu \mathrm{g}$ bid) or placebo for a total of 6 months. The use of salbutamol metered-dose inhaler (as needed), stable doses of theophylline, inhaled glucocorticosteroids and oral prednisone (the equivalent of $\leqslant 10 \mathrm{mg} \cdot \mathrm{day}^{-1}$ ) was permitted throughout the study period. Other inhaled long-acting bronchodilators were not allowed.

\section{Dyspnoea assessments}

Dyspnoea at baseline was assessed with the BDI and over the 6 months $(8,16$, and 24 weeks of therapy) by TDI [4]. BDI and TDI have three domains as follows: 1) functional impairment (FI), which determines the impact of breathlessness on the ability to carry out activities; 2) magnitude of task (MT), which determines the type of task that causes breathlessness; and 3) magnitude of effort (ME), which establishes the level of effort that results in breathlessness. The BDI score ranges from 0 (very severe impairment) to 4 (no impairment) for each domain and are summed to determine the BDI focal score $(0-12)$. The TDI score ranges from -3 (major deterioration) to +3 (major improvement) for each domain. The sum of all domains yields the TDI focal score $(-9$ to +9$)$. A change of at least 1 unit in TDI was used as the criterion for a minimal important meaningful difference, based on the inherent descriptions of the scale by the developers and the present authors' previous work that related a change of 1 unit in focal score to clinically meaningful effects [22].

The instrument was originally developed and validated in English and the instrument was translated to the individual native countries language for individual use.

Dyspnoea assessments, based on patient diaries (DD), were on a 0 (none) to 3 (severe) scale.

\section{Spirometry/patient health status}

Spirometry was performed on all clinic visits with FEV1 and FVC recorded. Generic and disease-specific health status was assessed using the multiple outcomes
Table 1. - The physicians global evaluation scale

\begin{tabular}{|c|c|}
\hline Category & Score \\
\hline Poor & $\begin{array}{l}1 \\
2\end{array}$ \\
\hline Fair & $\begin{array}{l}3 \\
4\end{array}$ \\
\hline Good & $\begin{array}{l}5 \\
6\end{array}$ \\
\hline Excellent & $\begin{array}{l}7 \\
8\end{array}$ \\
\hline
\end{tabular}

survey short form 36 [26] and St. George's respiratory questionnaire (SGRQ) [27-28] instruments, respectively. These instruments were administered at baseline and weeks 8, 16 and 24. Investigators recorded the COPD symptom scores, including dyspnoea, on a $0-3$ scale (none, mild, moderate, severe) after reviewing the patient's diary and then recorded a physician's global evaluation (PGE) of the patient's overall condition on a 1-8 scale (table 1). Patients tracked their "as needed" doses of salbutamol (one dose equals one to two puffs) on a daily diary.

\section{Statistical analysis}

Combined data from both trials were used for psychometric analysis. All randomised patients with baseline data and post-treatment data following multiple administration of treatment were included in the analysis. The differences between TDI responders (TDI $\geqslant 1$ unit at end of study) and nonresponders (TDI $<1$ unit at end of study) in spirometry, salbutamol use and health status scores were evaluated with analysis of variance. Pearson's correlation coefficient was used to examine the correlation between TDI and the results from the other outcomes. The number of patients with exacerbations during the study was compared using Fisher's exact test. An anchor-based approach was used to evaluate whether observable effects were meaningful [29-30] by relating mean TDI scores to the PGE.

\section{Results}

\section{Patients}

Further details of the population and the primary safety and efficacy findings have been reported by Donahue et al. [23] and BRusasco et al. [24]. Patient characteristics are listed in table 2 . On average, the population was $\sim 64$ yrs old, primarily male $(\sim 76 \%)$ and had moderate-to-severe disease based on spirometric criteria ( $40 \% \mathrm{FEV} 1$ pred).

\section{General patterns of measures}

The BDI score prior to treatment was $6.5 \pm 0.1$ (mean $\pm \mathrm{SE})$ for patients randomised to tiotropium, $6.5 \pm 0.1$ for patients randomised to salmeterol and 
Table 2. - Patient characteristics at screening

Placebo Salmeterol Tiotropium

\begin{tabular}{lccc}
\hline Total randomised n & 400 & 405 & 402 \\
Males \% & 76 & 75 & 77 \\
Age yrs & 64.6 & 64.1 & 63.8 \\
Duration of COPD yrs & 9.8 & 9.9 & 9.0 \\
Current smokers \% & 42.3 & 36.3 & 42.3 \\
Baseline spirometry & & & \\
$\quad$ FEV1 L & $1.09 \pm 0.40$ & $1.07 \pm 0.38$ & $1.12 \pm 0.39$ \\
FEV1 \% pred & $40.6 \pm 12.8$ & $39.4 \pm 12.2$ & $41.0 \pm 12.2$ \\
FVC L & $2.60 \pm 0.78$ & $2.55 \pm 0.77$ & $2.59 \pm 0.75$ \\
FEV 1/FVC \% & $42.3 \pm 9.2$ & $42.2 \pm 9.5$ & $43.7 \pm 9.7$ \\
\hline
\end{tabular}

Data are presented as mean \pm SD unless otherwise stated. COPD: chronic obstructive pulmonary disease; FEV1: forced expiratory volume in one second; FVC: forced vital capacity; pred: predicted. ${ }^{\#}$ : Morris criteria.

$6.5 \pm 0.1$ for patients assigned to placebo, indicating a population with moderate dyspnoea. The distribution of BDI focal scores for the group is illustrated in figure 1 . Forty-one $(4 \%)$ patients had an improvement of exactly 1 unit in TDI focal score; the responses within the three domains were distributed as follows: FI $(26 \%)$, ME (43\%), MT (31\%). There were improvements in only six of 41 patients who were TDI

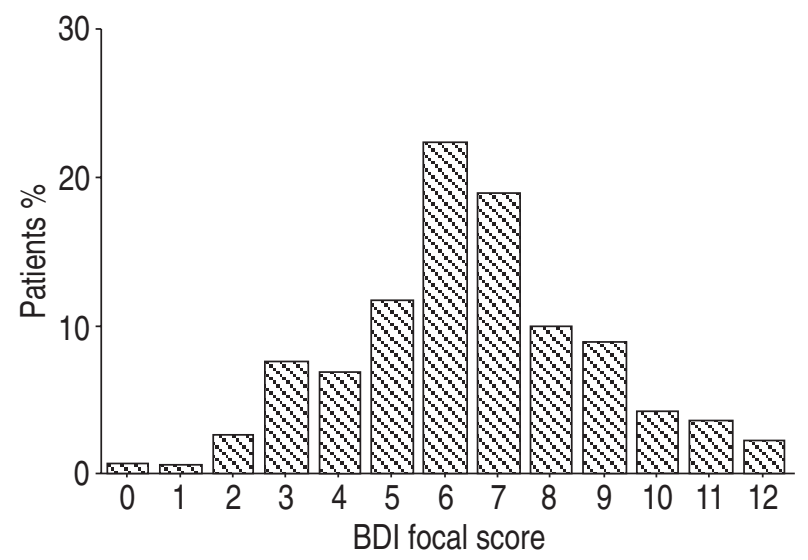

Fig. 1.-Frequency distribution of baseline dyspnoea index (BDI) focal score for the entire cohort at baseline. responders in one dimension and a decrement in another. Baseline dyspnoea index/transition dyspnoea index
associated with other measures

Correlations of BDI (cross-sectional) and TDI (longitudinal) with other outcomes are listed in tables 3 and 4. The correlations for BDI ranged from -0.35 -0.64 for SGRQ scores and was 0.31 for FEV1 $(p<0.05)$; correlations were lowest in the symptom domain. The BDI score also correlated with the DD score $(r=-0.34$; $\mathrm{p}<0.05$ ), demonstrating concurrent validity. This pattern of correlations was the same in English and nonnative English countries. The correlations between SGRQ and DD were consistently greater in the non-native English-speaking countries; nevertheless, both cohorts demonstrated statistically significant associations. Correlations between TDI and changes in SGRQ scores ranged from -0.32--0.40. For the association of the changes in TDI and SGRQ, correlations, although significant for both groups, were of greater magnitude in the English-speaking cohort. Unlike correlations at baseline, the association of changes in DD with changes in SGRQ were greater in the native English-speaking cohort. Concurrent validity for TDI can be seen in the association with the changes recorded on the DD $(r=-0.29 ; \mathrm{p}<0.05)$.

BDI was correlated with PGE at baseline ( $\mathrm{r}=0.39$; $\mathrm{p}<0.01)$ as was TDI with the changes in PGE over $1 \mathrm{yr}(\mathrm{r}=0.28 ; \mathrm{p}<0.05)$. Figure 2 illustrates the frequency distribution of PGE at the end of the study for all subjects and the corresponding mean values for TDI. The mean TDI scores were in the range of 1 unit with a $1-2$ point change in PGE.

\section{Transition dyspnoea index response and other clinical assessments}

Figure 3 illustrates the supplemental salbutamol use classified by TDI responder status of the cohort. There was significantly less salbutamol use $(p<0.05)$ in those patients who had at least a 1-unit improvement in TDI at the end of study versus those who did not.

Table 3. - The association of the baseline dyspnoea index (BDI) and transition dyspnoea index focal scores with other respiratory outcome measures

\begin{tabular}{|c|c|c|c|c|c|c|}
\hline & \multicolumn{2}{|c|}{ Total cohort } & \multicolumn{2}{|c|}{ Native English countries } & \multicolumn{2}{|c|}{ Non-native English countries } \\
\hline & BDI & DD baseline & BDI & DD baseline & BDI & DD baseline \\
\hline SGRQ symptom baseline & -0.35 & 0.34 & -0.35 & 0.26 & -0.34 & 0.35 \\
\hline SGRQ activity baseline & -0.63 & 0.44 & -0.68 & 0.35 & -0.61 & 0.46 \\
\hline SGRQ impact baseline & -0.59 & 0.36 & -0.58 & 0.30 & -0.60 & 0.40 \\
\hline SGRQ total baseline & -0.64 & 0.44 & -0.65 & 0.36 & -0.64 & 0.47 \\
\hline DD score baseline & -0.34 & & -0.34 & & -0.34 & \\
\hline FEV1 baseline & 0.31 & -0.26 & 0.32 & -0.21 & 0.29 & -0.26 \\
\hline FVC baseline & 0.25 & -0.18 & 0.21 & -0.11 & 0.27 & -0.19 \\
\hline PGE baseline & 0.39 & -0.46 & 0.39 & -0.40 & 0.38 & -0.48 \\
\hline
\end{tabular}

DD: dyspnoea diary; SGRQ: St. George's respiratory questionnaire; FEV1: forced expiratory volume in one second; FVC: forced vital capacity; PGE: physician's global evaluation. 
Table 4. - The association of transition dyspnoea index (TDI) focal scores with other respiratory outcome measures at the end of 6 months

\begin{tabular}{|c|c|c|c|c|c|}
\hline \multicolumn{2}{|c|}{ Total cohort } & \multicolumn{2}{|c|}{$\begin{array}{l}\text { Native English speaking } \\
\text { countries }\end{array}$} & \multicolumn{2}{|c|}{$\begin{array}{l}\text { Non-native English speaking } \\
\text { countries }\end{array}$} \\
\hline TDI & $\begin{array}{l}\text { DD change } \\
\text { from baseline }\end{array}$ & TDI & $\begin{array}{l}\mathrm{DD} \text { change } \\
\text { from baseline }\end{array}$ & TDI & $\begin{array}{l}\text { DD change } \\
\text { from baseline }\end{array}$ \\
\hline-0.33 & 0.27 & -0.41 & 0.35 & -0.29 & 0.23 \\
\hline-0.33 & 0.23 & -0.37 & 0.29 & -0.31 & 0.19 \\
\hline-0.32 & 0.26 & -0.38 & 0.31 & -0.30 & 0.23 \\
\hline-0.40 & 0.31 & -0.46 & 0.37 & -0.38 & 0.27 \\
\hline-0.29 & & -0.35 & & -0.25 & \\
\hline 0.21 & -0.23 & 0.24 & -0.24 & 0.19 & -0.22 \\
\hline 0.16 & -0.21 & 0.18 & -0.21 & 0.16 & -0.21 \\
\hline 0.28 & -0.47 & 0.29 & -0.45 & 0.27 & -0.48 \\
\hline
\end{tabular}

DD: dyspnoea diary; SGRQ: St. George's respiratory questionnaire; FEV1: forced expiratory volume in one second; FVC: forced vital capacity; PGE: physician's global evaluation.
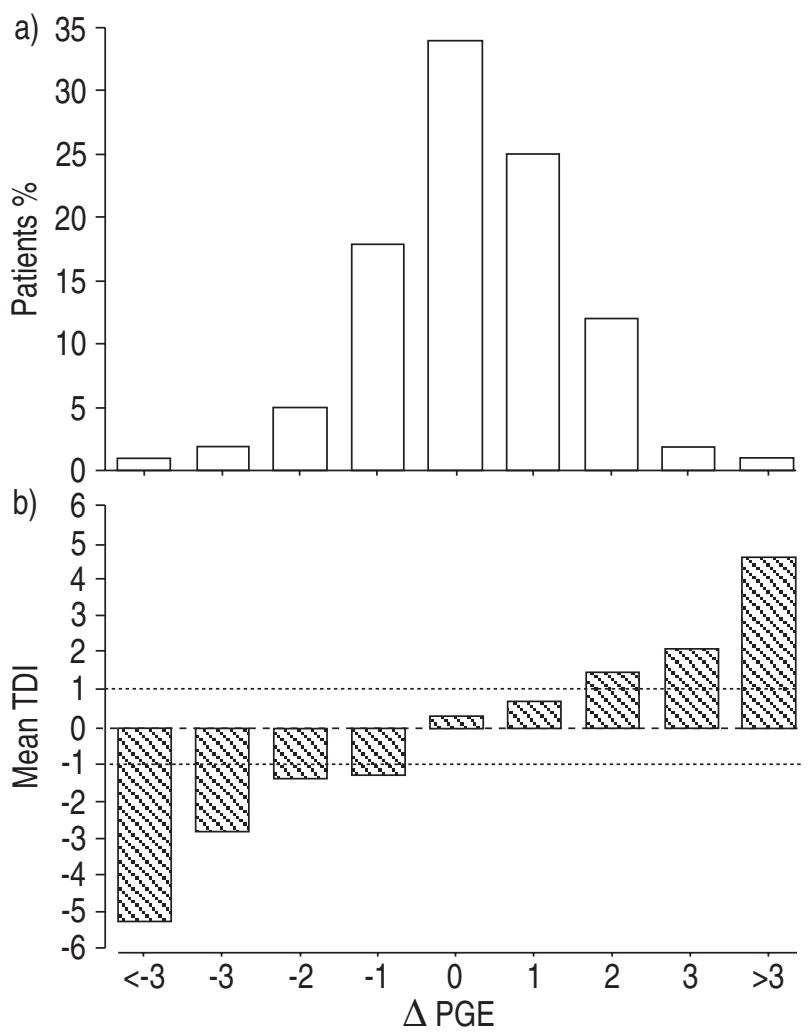

Fig. 2.-a) Frequency distribution of changes in physician's global evaluation (PGE) and b) the corresponding mean values for transition dyspnoea index (TDI). The mean TDI scores were in the range of 1 unit $(\cdots \cdots)$ with a 1-2 point change in PGE.

Additionally, there was an increase in salbutamol use over time in nonresponders that was not evident in responders. Spirometric response was also greater in responders (table 5). A significantly smaller proportion of responders experienced an exacerbation event that corresponded to significantly less events per year (table 5). Furthermore, health status scores measured by SGRQ were significantly improved in those classified as dyspnoea responders, with a mean effect size regarded as clinically meaningful (i.e. change of 4 units). The differences were also evident when the cohort was classified by native versus non-native English speaking populations.

\section{Discussion}

Breathlessness is an important symptom in patients suffering from chronic lung disease and the limitations that dyspnoea poses are often the reason for patients seeking medical attention. Thus, any medications proven to relieve dyspnoea are an important component of therapy. Demonstrating the relief of dyspnoea with drug therapy depends on achieving consistent results using valid instruments. The current results have validated the TDI instrument in a multinational clinical trial setting and confirmed the validation and its use in participants residing in both English and non-native English-speaking countries that participated in the trial.

The BDI and TDI have been validated over their development [5-8] and the TDI has been shown to be responsive to a wide variety of interventions [9-20].

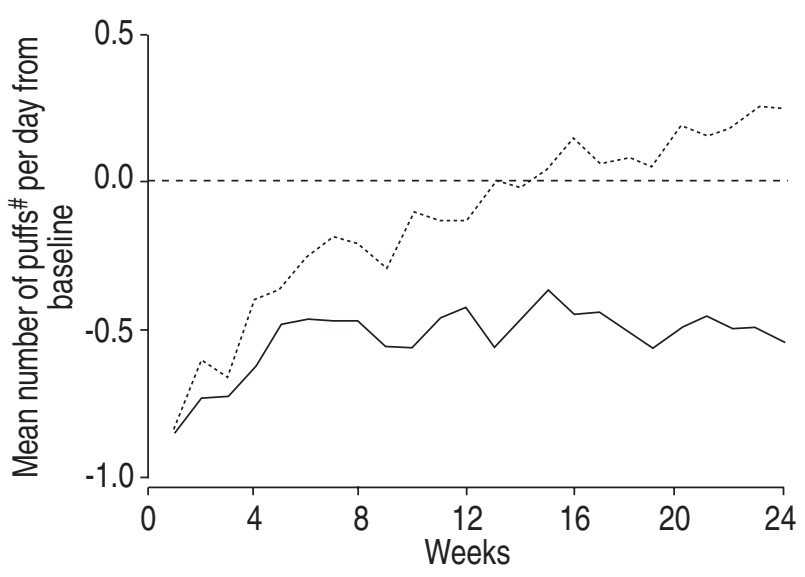

Fig. 3.-Change from baseline in mean salbutamol use for transition dyspnoea index (TDI) responders (focal score $\geqslant 1$; $\mathrm{n}=382 ;-)$ and nonresponders $(\mathrm{n}=615 ; \cdots \cdots)$. \#: 1 puff $=100 \mu \mathrm{g}$ salbutamol. $\mathrm{p}<0.05$ TDI responders versus TDI nonresponders. 
Table 5. - Relationship between transition dyspnoea index (TDI) response and exacerbation over the study period/health status scores at end of study

\begin{tabular}{|c|c|c|c|c|c|c|}
\hline & \multicolumn{2}{|c|}{ Total cohort } & \multicolumn{2}{|c|}{$\begin{array}{l}\text { Native English countries TDI } \\
\text { focal score } 1\end{array}$} & \multicolumn{2}{|c|}{$\begin{array}{l}\text { Non-native English countries } \\
\text { TDI focal score } 1\end{array}$} \\
\hline & TDI R & TDI NR & TDI R & TDI NR & TDI $\mathrm{R}$ & TDI NR \\
\hline $\begin{array}{l}\text { Subjects } \mathrm{n} \\
\text { Exacerbations }\end{array}$ & 382 & 615 & 135 & 252 & 247 & 363 \\
\hline \multicolumn{7}{|l|}{ Exacerbations } \\
\hline Patients with event $\%$ & $29.8^{*}$ & 39.0 & $30.4^{* *}$ & 41.7 & 29.6 & 37.2 \\
\hline Events per patient yr & $0.872^{*}$ & 1.358 & $0.901 * *$ & 1.399 & $0.857 * *$ & 1.329 \\
\hline \multicolumn{7}{|l|}{ Health Status } \\
\hline SGRQ total score & $-8.8 \pm 0.6^{* *}$ & $0.9 \pm 0.5$ & $-12.0 \pm 1.1^{*}$ & $-1.2 \pm 0.8$ & $-7.0 \pm 0.8^{*}$ & $2.3 \pm 0.6$ \\
\hline SGRQ impacts score & $-7.7 \pm 0.3 * *$ & $1.3 \pm 0.6$ & $-11.3 \pm 1.2^{*}$ & $-1.0 \pm 0.9$ & $-5.9 \pm 0.9 *$ & $2.8 \pm 0.7$ \\
\hline SGRQ symptom score & $-13.6 \pm 1.2 *$ & $0.6 \pm 0.8$ & $-18.3 \pm 1.9^{*}$ & $-3.1 \pm 1.3$ & $-11.3 \pm 1.4^{*}$ & $3.1 \pm 1.1$ \\
\hline SGRQ activity score & $-7.7 \pm 0.8^{*}$ & $0.4 \pm 0.5$ & $-9.6 \pm 1.2^{*}$ & $-0.4 \pm 0.9$ & $-6.4 \pm 0.9^{*}$ & $0.99 \pm 0.7$ \\
\hline \multicolumn{7}{|l|}{ Spirometry } \\
\hline Trough FEV1 & $0.08 \pm 0.01 *$ & $0.01 \pm 0.01$ & $0.13 \pm 0.02 *$ & $0.03 \pm 0.01$ & $0.05 \pm 0.02 * *$ & $-0.01 \pm 0.01$ \\
\hline Trough FVC & $0.17 \pm 0.03^{*}$ & $0.05 \pm 0.02 * *$ & $0.28 \pm 0.04 *$ & $0.11 \pm 0.03 *$ & $0.12 \pm 0.03^{*}$ & $0.01 \pm 0.03$ \\
\hline
\end{tabular}

Data are presented as mean \pm SE unless otherwise stated. R: responders; NR: nonresponders; SGRQ: St. George's respiratory questionnaire; FEV1: forced expiratory volume in one second; FVC: forced vital capacity. ": A change of 4 units in SGRQ is clinically meaningful. *: $\mathrm{p}<0.05 ; * *: \mathrm{p}<0.001$, responders versus nonresponders.

The large cohort in the clinical trials evaluating efficacy of the bronchodilator tiotropium afforded the opportunity to validate the BDI/TDI instrument in a multinational setting. The observations in this multinational trial confirm the current authors' findings in previous studies in the USA [22], in that concurrent and construct validity were established. In other words, the two dyspnoea measures (BDI/TDI and DD) were significantly associated as were the BDI and TDI with other spirometric and outcome measures at baseline and after 6 month of therapy, respectively.

While all correlations of the BDI and TDI with SGRQ total and individual domain scores were significant, the BDI correlation with SGRQ symptom was weaker $(\mathrm{r}=-0.35)$ than other domains such as activity $(r=-0.63)$. This may reflect the fact that the SGRQ symptom score includes both cough and sputum and the discriminative BDI reflects primarily dyspnoea with activity. This difference among domains was lost in the association of the changes in these measures over the trial (i.e. TDI versus $\Delta \mathrm{SGRQ}$ ).

DD scores did not show large differences in correlations across SGRQ total scores and domains at baseline $(r=0.34-0.44)$ or with changes over time $(\mathrm{r}=0.23-0.31)$. The overall high correlations of baseline measures versus the correlation of changes likely reflect the tighter distribution of the changes (i.e. transition versus the discriminative relationships at baseline).

The associations in this study were evident in both the entire cohort as well as when the cohort was evaluated by native language relative to the Englishbased BDI/TDI. In summary, the instrument's concurrent and construct validity remained when the English version or translated versions was utilised. This observation was not surprising, as the TDI instrument itself serves as a general guide to open-ended questions as opposed to requesting specific answers to specific questions. The present authors did observe some differences in the English and non-English speaking countries, in that correlations between baseline measures of SGRQ and the DD were greater in the non-native English speaking countries. Conversely, the SGRQ changes correlated more strongly with TDI and DD changes in the English speaking cohort. Whether these differences represent chance findings or reflect some methodological aspects of the trial are unknown. Nevertheless, the significance of all correlations across both groups is the most relevant observation for the instrument's overall validity.

Another important finding was the demonstration that a small change in TDI was seen to be relevant when assessed against an overall global change as judged by the clinician. The approximate net change of 1 unit is inherent in the descriptors of the instrument and in this cohort those with at least a 1-unit change in focal score had fewer exacerbations and improved health status and greater spirometric improvement relative to those who did not achieve a 1-unit improvement in TDI. For the SGRQ symptom score, the TDI responder cohort had a mean score nearly 3 times what is regarded as clinically meaningful. Additionally, TDI responders used significantly less salbutamol that those not improving their breathlessness.

In conclusion, the baseline and the transition dyspnoea indices have been validated in a multinational clinical trial cohort. The change of 1 unit was confirmed as having clinical relevance based on its relationship to an overall global change, as well as the improved outcomes observed in those who demonstrated improvements in breathlessness by at least a 1-unit focal score in transition dyspnoea index.

\section{References}

1. Mahler DA. Dyspnea: diagnosis and management. Clin Chest Med 1987; 8: 215-230.

2. Official Statement of the ATS. Dyspnea. Mechanisms, assessment, and management: a consensus statement. 
American Thoracic Society. Am J Respir Crit Care Med 1999; 159: 321-340.

3. Pauwels RA, Buist AS, Calverley PM, Jenkins CR, Hurd SS and the GOLD Scientific Committee. Global strategy for the diagnosis, management, and prevention of chronic obstructive pulmonary disease. NHLBI/ WHO Global Initiative for Chronic Obstructive Lung Disease (GOLD) Workshop summary. Am J Respir Crit Care Med 2001; 163: 1256-1276.

4. Mahler DA, Guyatt GH, Jones PW. Clinical measurement of dyspnea. In: Mahler DA, ed. Dyspnea. New York, Marcel Dekker, Inc, 1998; pp. 149-198.

5. Mahler DA, Weinberg DH, Wells CK, Feinstein AR. The measurement of dyspnea: contents, interobserver agreement, and physiologic correlates of two new clinical indexes. Chest 1984; 85: 751-758.

6. Eakin EG, Sassi-Dambron DE, Ries AL, Kaplan RM. Reliability and validity of dyspnea measures in patients with obstructive lung disease. Int $J$ Behavioral Med 1995; 2: 118-134.

7. Mahler DA, Wells CK. Evaluation of clinical methods for rating dyspnea. Chest 1988; 93: 580-586.

8. Mahler DA, Harver A, Rosiello RA, Daubenspeck JA. Measurement of respiratory sensation in interstitial lung disease: evaluation of clinical dyspnea ratings and magnitude scaling. Chest 1989; 96: 767-771.

9. Casaburi R, Mahler DA, Jones PW, et al. A long-term evaluation of once-daily inhaled tiotropium in chronic obstructive pulmonary disease. Eur Respir J 2002; 19: 217-224.

10. Vincken W, van Noord JA, Greefhorst APM, et al. Improved health outcomes in patients with COPD during $1 \mathrm{yr}^{\prime} \mathrm{s}$ treatment with tiotropium. Eur Respir $J$ 2002; 19: 209-216.

11. Mahler DA, Donohue JF, Barbee RA, et al. Efficacy of salmeterol xinafoate in the treatment of COPD. Chest 1999; 115: 957-965.

12. Mahler DA, Matthay RA, Snyder PE, Wells CK, Loke J. Sustained-release theophylline reduces dyspnea in nonreversible obstructive airway disease. Am Rev Respir Dis 1985; 131: 22-25.

13. Kirsten DK, Wegner RE, Jorres RA, Magnussen H. Effects of theophylline withdrawal in severe chronic obstructive pulmonary disease. Chest 1993; 104: 1101-1107.

14. Martinez FJ, de Oca MM, Whyte RI, Stetz J, Gay SE, Celli BR. Lung-volume reduction improves dyspnea, dynamic hyperinflation, and respiratory muscle function. Am J Respir Crit Care Med 1997; 155: 1984 1990.

15. Ramirez-Venegas A, Ward JL, Olmstead EM, Tosteson AN, Mahler DA. Effect of exercise training on dyspnea measures in patients with chronic obstructive pulmonary disease. $J$ Cardiopulmonary Rehab 1997; 17: 103-109.

16. Foglio K, Bianchi L, Bruletti G, Battista L, Pagani M, Ambrosino N. Long-term effectiveness of pulmonary rehabilitation in patients with chronic airway obstruction. Eur Respir J 1999; 13: 125-132.
17. Reardon J, Awad E, Normandin E, Vale F, Clark B, ZuWallack RL. The effect of comprehensive outpatient pulmonary rehabilitation on dyspnea. Chest 1994; 105: 1046-1052.

18. O'Donnell DE, McGuire MA, Samis L, Webb, KA. The impact of exercise reconditioning on breathlessness in severe chronic airflow limitation. $\mathrm{Am}$ J Respir Crit Care Med 1995; 152: 2005-2013.

19. Lisboa C, Munoz V, Beroiza T, Leiva A, Cruz E. Inspiratory muscle training in chronic airflow limitation: comparison of two different training loads with a threshold device. Eur Respir J 1994; 7 : 1266-1274.

20. Harver A, Mahler DA, Daubenspeck JA. Targeted inspiratory muscle training improves respiratory muscle function and reduces dyspnea in patients with chronic obstructive pulmonary disease. Ann Intern Med 1989; 111: 117-124.

21. Mahler DA, Tomlinson D, Olmstead EM, Tosteson NA, O'Conner GT. Changes in dyspnea, health status, and lung function in chronic airway disease. Am J Respir Crit Care Med 1995; 151: 61-65.

22. Witek TJ, Mahler DA. Meaningful effect size and patterns of response of the transition dyspnea index. $J$ Clin Epidemiol 2003 (in press).

23. Donohue JF, van Noord JA, Bateman ED, et al. A 6-month, placebo-controlled study comparing lung function and health status changes in COPD patients treated with tiotropium or salmeterol. Chest 2002; 122 : 47-55.

24. Brusasco V, Thompson P, Vincken W, Lee A, Towse L, Witek TJ. Improvement of dyspnea following six months treatment with tiotropium but not with salmeterol in patients with COPD. Eur Respir $J$ 2001; Suppl. 33, P286.

25. American Thoracic Society. Standards for the diagnosis and care of patients with chronic obstructive pulmonary disease (COPD). Am J Respir Crit Care Med 1995; 152: S77-S120.

26. Ware JE, Sherbourne CD. The MOS 36-item shortform health survey (SF-36): I. Conceptual framework and item selection. Med Care 1992; 30: 472-483.

27. Jones PW, Quirk FH, Baveystock CM, Littlejohns P. A self-complete measure for chronic airflow limitation - the St George's Respiratory Questionnaire. Am Rev Respir Dis 1992; 145: 1321-1327.

28. Jones PW. Interpreting thresholds for a clinically significant change in health status in asthma and COPD. Eur Respir J 2002; 19: 398-404.

29. Samsa G, Edelman D, Rothman ML, Williams GR, Lipscomb J, Matchar D. Determining clinically important differences in health status measures: A general approach with illustration to the health utilities index mark II. Pharmacoeconomics 1999; 15: 141-155.

30. Redelmeier D, Guyatt GH, Goldstein RS. Assessing the minimal important difference in symptoms: a comparison of two techniques. J Clin Epidemiol 1996; 49: 1215-1219. 